\title{
Technological Task Force Report
}

$\mathrm{T}$ he American Political Science Association Taskforce on Technological Innovation in Political Science conducted a series of meetings and conference calls to examine ways that APSA and its members can encourage technology innovations in teaching, research, and public outreach. The taskforce formed a set of subcommittees, and each group generated a number of ideas, which are briefly summarized in the following text. The taskforce also conducted a survey of APSA members regarding their technology use. These recommendations arose from longer subcommittee reports outlining the rationale for these recommendations, available online at apsanet.org/reports.

\section{ACADEMIC COMMON GOODS}

Create a call and award a monetary prize with a $\$ 25$,00o endowment focused on teaching innovations. In addition to a cash award, the prize should have a prestigious name such as the Elinor Ostrom Award; it should be widely publicized and the results broadly disseminated. Perhaps an APSA member committee should identify the problem to be solved that year, after which competitors would submit proposed solutions. Then, the committee determines the prize winner.

\section{TEACHING}

1. Centralize teaching and learning resources on the APSAnet website home page in one main tab with a pulldown menu.

2. Create a peer-reviewed teaching resources library that is accessible through APSAnet, modeled on the Teaching Resources and Innovations Library for Sociology (TRAILS) site at the American Sociological Association or Multimedia Educational Resource for Learning and Online Teaching (MERLOT) by the California State University system, including a repository of images that professors could use, free of charge, in their instructional materials.

3. Partner with existing centers for teaching and learning to enable
APSA members' access to their content and/or enable political science educators to earn "Teaching Certificates" through these institutions.

\section{TEXTUAL ANALYSIS/LANGUAGE} TRANSLATION

APSA should create or facilitate platforms for:

1. text mining, for example, of "canonical" texts in the history of political thought, the writings and speeches of political figures, or textual production of broader public spheres;

2. techniques by which large- $\mathrm{N}$ data are converted into visual representations of patterns that human interpreters of texts and contexts might otherwise overlook;

3. "crowd sourcing," or harnessing energy and local knowledge of technologically enabled social networks of scholars, citizen activists, and government agencies to generate new knowledge;

4. machine translation to produce new databases that could be analyzed using both digital and conventional methods.

\section{PUBLISHING}

1. Create a preprint server in which peer-reviewed analyses appear before print publication (this can be expensive).

2. Because books are developing online platforms, develop a better system for alerting people to the publication of a book of particular interest to them.

3. Host a keyword-searchable table of contents for a wide array of journals, arguably including some outside political science.

\section{DATA CAPTURING FOR TEACHING AND RESEARCH}

1. Create a permanent online archive of temporal data for researchers.
2. Develop a "Forever Data" website.

3. Tailor content for APSA members.

\section{RESOURCE CONSIDERATIONS FOR} APSA

1. Fund-raising, with naming opportunity, for prize;

2. Private sector partnerships or grants from Google/Facebook, or other bigdata sources (especially those with political scientists on staff);

3. Share resources with other associations (e.g., join in TRAILS; connect with International Studies Association with its 7,00o members);

4. Pool resources with educational institutions (e.g., around teaching and software development).

\section{SPECIFIC SUGGESTIONS BASED}

ON THE APSA MEMBER SURVEY

1. Create an online, peer-reviewed library to centralize teaching resources.

2. Pursuant to creating a library of resources, develop a more accessible, reviewable, updatable, well-organized syllabi repository.

3. Develop and deliver a series of continual, online workshops regarding teaching/pedagogy independent of the annual APSA Teaching and Learning Conference.

4. Pursuant to creating a library of resources, curate a collection of internship-related materials that would be of particular interest to faculty in BA- and MA-granting programs.

5. Develop online course resources that would particularly benefit faculty in AA- and MA-granting programs. 